\title{
A simple method for mouse embryo cryopreservation in a low toxicity vitrification solution, without appreciable loss of viability
}

\author{
M. Kasai, J. H. Komi, A. Takakamo, H. Tsudera, T. Sakurai and \\ T. Machida
}

Laboratory of Animal Science, College of Agriculture, Kochi University, Nankoku, Kochi 783, Japan

\begin{abstract}
Summary. Mouse morulae were exposed to solutions containing 30-50\% of permeable agents (ethylene glycol, glycerol, propylene glycol) in modified phosphate-buffered saline (PBl medium) at $20^{\circ} \mathrm{C}$ for $20 \mathrm{~min}$. A high percentage of them developed to expanded blastocysts in culture, after exposure to $30 \%$ and $40 \%$ ethylene glycol ( 98 and $84 \%$, respectively), or $30 \%$ glycerol $(88 \%)$. Ethylene glycol and glycerol were diluted to 30 and $40 \%$ with PB1 medium or with PB1 containing $30 \%$ Ficoll or $30 \%$ Ficoll $+0.5 \mathrm{M}$-sucrose, immersed in liquid nitrogen in straws and warmed in $20^{\circ} \mathrm{C}$ water. Solutions containing $40 \%$ of a permeable agent with Ficoll did not crystallize during cooling or warming. Mouse morulae were exposed to $40 \%$ ethylene glycol in PB1 medium containing 30\% Ficoll (EF) or PB1 medium $+30 \%$ Ficoll $+0.5 \mathrm{M}-$ sucrose (EFS) for 5-20 min at $20^{\circ} \mathrm{C}$. EFS solution was non-toxic to the embryos during $5 \mathrm{~min}$ of exposure. When embryos, equilibrated in EFS solution for 2 or $5 \mathrm{~min}$ at $20^{\circ} \mathrm{C}$, were vitrified at $-196^{\circ} \mathrm{C}$ and were warmed rapidly, nearly all embryos developed in culture (97-98\%), and $51 \%$ developed to live young at term after transfer. This method, which results in virtually no decrease in embryonic viability, may be of practical use for embryo preservation.
\end{abstract}

Keywords: mouse; embryo; vitrification; ethylene glycol; sucrose; Ficoll

\section{Introduction}

The embryo freezing technique first reported by Whittingham et al. (1972) has been one of the most reliable methods for embryo preservation, and is widely used (Wood et al., 1987). Most attempts to improve the technique, therefore, have been directed to simplification of procedures (Wood \& Farrant, 1980; Kasai et al., 1980; Miyamoto \& Ishibashi, 1986; Széll \& Shelton, 1986a; Trounson et al., 1987). Among such attempts, vitrification (Rall \& Fahy, 1985) is a significant advance, in which embyros are suspended in a highly concentrated solution which can be cooled to liquid nitrogen temperaures without crystallizing. However, the initial vitrification solution (VS1) was highly toxic and embryos must be exposed to this solution at $\sim 4^{\circ} \mathrm{C}$, which reduces the practicality of the technique. In addition, embryos must be equilibrated in VS1 in a stepwise manner for 20-35 min at 2 different temperatures before being plunged into liquid nitrogen.

Vitrification, however, has potential advantages over conventional methods in that it takes only a few seconds for cooling embryos, and there is no extracellular crystallization, which is one of the major causes of cell injury. Besides simplification of the procedures, the most important requirement of an embryo preservation technique must be to maintain high survival. In this paper, we describe a simple method for embryo storage by vitrification, which results in extremely high survival rates. 


\section{Materials and Methods}

Embryos. Female ICR mice (6-12 weeks old; CLEA Japan, Inc., Tokyo, Japan) were induced to superovulate by i.p. injections of 5 i.u. PMSG (Serotropin: Teikokuzoki, Tokyo, Japan) and 5 i.u. hCG (Puberogen: Sankyozoki, Tokyo, Japan) given $48 \mathrm{~h}$ apart. Females were mated with ICR male mice, except for the embryo transfer experiment, for which $\mathrm{C} 3 \mathrm{H}$ males were used. Embryos were flushed from the upper half of the excised uteri and a region of the oviducts with modified phosphate-buffered saline (PB1: Whittingham, 1971) 77-79 h after the injection of hCG. The embryos were washed in fresh $\mathrm{PB} 1$ medium and only morphologically normal, compacted morulae were used.

Experiments involving suspension of embryos in cryoprotectant solutions were conducted in a room at $20 \pm 0 \cdot 5^{\circ} \mathrm{C}$.

Vitrification solutions. As candidates for a basic agent to compose a new vitrification solution, 3 permeable cryoprotectants, ethylene glycol, glycerol and propylene glycol, were examined. Non-permeable agents were Ficoll 70 (average molecular weight 70000 ; Pharmacia, Uppsala, Sweden) as a macromolecule to assist vitrification, and sucrose as a low molecular weight compound which causes embryo shrinkage by osmosis.

Toxicity test of cryoprotectants. In the first series of experiments, the toxicity of individual permeable cryoprotectants was tested. Embryos (9-10) were suspended in $100 \mu \mathrm{l}$ PB1 medium containing a permeable cryoprotectant at a concentration of 30,40 or $50 \%(\mathrm{v} / \mathrm{v})$ under paraffin oil (Nacalai Tesque, Inc., Kyoto, Japan) in a culture dish $\left(35 \times 10 \mathrm{~mm}\right.$, Nunc Inc., Naperville, IL, USA) at $20^{\circ} \mathrm{C}$. After $20 \mathrm{~min}$, embryos were transferred to PB 1 medium containing the same agent (the same concentration) $+0.5 \mathrm{M}$-sucrose, then to $\mathrm{PB} 1$ medium containing $0.5 \mathrm{M}$-sucrose (S-PBl), and then to fresh PB1 medium at 5-min intervals at $20^{\circ} \mathrm{C}$.

In the second series of experiments, the toxicity of 2 vitrification solutions was tested. Embryos (9-10) were suspended in $40 \%$ ethylene glycol diluted in PB1 medium containing either 30\% Ficoll (EF solution) or 30\% Ficoll + $0.5 \mathrm{M}$-sucrose (EFS solution) under paraffin oil in a culture dish at $20^{\circ} \mathrm{C}$. Final concentrations of Ficoll and sucrose were, therefore, $18 \%$ and $0.3 \mathrm{M}$, respectively. After holding for $5,10,15$ or $20 \mathrm{~min}$ at $20^{\circ} \mathrm{C}$, embryos in EF solution were transferred successively to EFS solution, S-PB1 medium and fresh PB1 medium at 5-min intervals. Those in EFS solution were transferred directly to S-PB1 medium and then to fresh PB1 medium 5 min later.

Recovered embryos were washed in a modified Krebs-Ringer-bicarbonate (KRB) medium (Toyoda \& Chang, 1974) and were cultured in $\sim 0.3 \mathrm{ml}$ of the medium under paraffin oil in $5 \% \mathrm{CO}_{2}$ in air at $37^{\circ} \mathrm{C}$. The survival of the embryos was assessed by their ability to develop into expanded blastocysts during $48 \mathrm{~h}$ of culture.

Experiments were replicated 4-5 times, with 39-50 embryos being tested for each treatment.

Vitrification test of media. Ethylene glycol and glycerol were diluted to a concentration of 30 or $40 \%$ with PB1 medium or PB1 medium containing 30\% Ficoll or 30\% Ficoll $+0.5 \mathrm{M}$-sucrose. The solutions were introduced into 0.25-mi plastic straws, and were immersed directly into liquid nitrogen. After being held for about $10 \mathrm{sec}$, they were quickly transferred into $20^{\circ} \mathrm{C}$ water and agitated gently. According to the appearance of the straws in liquid nitrogen and in $20^{\circ} \mathrm{C}$ water, samples which remained transparent were considered uncrystallized, and those which turned opaque were considered crystallized.

Experiments were replicated 6 times using two types of plastic straws (Fujihirakogyo, Tokyo, Japan; I.M.V., L'Aigle, France). A solution was scored as crystallizing if the solution turned opaque one or more times.

Vitrification of embryos. EFS solution was prepared in a $0 \cdot 25-\mathrm{ml}$ plastic straw by successive aspiration of S-PB 1 medium $(\sim 100 \mu \mathrm{l})$, air $(\sim 20 \mu \mathrm{l})$, EFS solution $(\sim 6 \mu \mathrm{l})$, air $(\sim 6 \mu \mathrm{l})$ and EFS solution $(\sim 40 \mu \mathrm{l})$, with a 1-ml syringe connected by a small silicone tube, and the straw was held horizontally at $20^{\circ} \mathrm{C}$ (Fig. la). Embryos (8-11) were suspended in EFS solution at $20^{\circ} \mathrm{C}$ in a watch glass, and were washed in the solution once. They were transferred to the larger column of EFS solution $(\sim 40 \mu \mathrm{l})$, and then air $(\sim 6 \mu \mathrm{l})$, EFS solution $(\sim 6 \mu \mathrm{l})$, air $(\sim 15 \mu \mathrm{l})$ and S-PBI medium $(\sim 20 \mu \mathrm{l})$ were aspirated successively (Fig. lb) before being sealed with the powder. At 2,5 or 10 min exposure of embryos to the solution, straws were immersed in liquid nitrogen vertically in two steps, in order to prevent bursting of straws: first, about a half of the straw, including the EFS solution, was immersed rapidly, and then the rest of the straw, including the larger column of S-PB1 $(\sim 100 \mu 1)$, was immersed slowly. After storage for 2-125 days, the straws were warmed rapidly in $20^{\circ} \mathrm{C}$ water. As soon as the crystallized S-PB1 medium in the straw began to melt (about $5 \mathrm{sec}$ ), embryos in the vitrification solution were expelled into a watch glass by flushing the straw with $\sim 0.8 \mathrm{ml}$ $\mathrm{S}-\mathrm{PB} 1$ medium, agitated gently, and then transferred into fresh $\mathrm{S}-\mathrm{PB} 1$ medium at $20^{\circ} \mathrm{C}$. At about 5 min after flushing out, embryos were transferred to fresh PB1 medium.

In-vitro survival of the embryos was assessed as described above. To examine the developmental potential in vivo, $\mathrm{Fl}$ embryos $(\mathrm{C} 3 \mathrm{H} \times \mathrm{ICR})$ were vitrified after exposure to EFS solution for 2 or $5 \mathrm{~min}$. They were warmed approximately $12 \mathrm{~h}$ in advance of the time when synchrony between embryos and recipient uteri was expected, so that embryos were slightly older than uteri. They were cultured for $\mathrm{l}-6 \mathrm{~h}$ before being transferred into one or both uterine horns (4-8 per horn (average of 6) and 6-15 per recipient (average of 10.5)) of recipient mice of the ICR strain on Day 3 of pseudopregnancy, induced by mating with a vasectomized ICR male. The recipients were allowed to litter.

Statistics. Data were analysed by $\chi^{2}$ tests. 
(a)

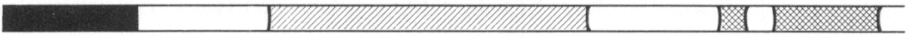

(b)

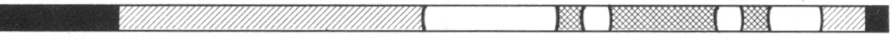

\section{EFS solution $\quad \square$ Air \\ S-PB1 medium Plug}

Fig. 1. Diagram of a $0 \cdot 25-\mathrm{ml}$ straw just before loading embryos (a), and just before cooling in liquid nitrogen (b), showing the configuration of EFS solution, S-PB1 medium, air and plug.

\section{Results}

\section{Toxicity test of cryoprotectants}

As shown in Table 1, when mouse morulae were exposed to a $30 \%$ solution of permeable cryoprotectants for $20 \mathrm{~min}$ at $20^{\circ} \mathrm{C}$, the percentage of embryos developing to expanded blastocysts in culture was high in ethylene glycol $(98 \%)$ and glycerol $(88 \%)$, but was low $(P<0.001)$ in propylene glycol $(16 \%)$. After exposure to $40 \%$ solution of permeable agents, only embryos exposed to ethylene glycol showed a high percentage development $(84 \%)$. However, embryos did not survive exposure to $50 \%$ ethylene glycol.

Table 1. Survival of mouse morulae exposed to permeable cryoprotectants for $20 \mathrm{~min}$ at $20^{\circ} \mathrm{C}$

\begin{tabular}{|c|c|c|c|}
\hline \multirow[b]{3}{*}{ Cryoprotectants } & \multicolumn{3}{|c|}{$\begin{array}{c}\text { No. of embryos developed/no. of embryo } \\
\text { treated }(\%)\end{array}$} \\
\hline & \multicolumn{3}{|c|}{ Concentration of cryoprotectants } \\
\hline & $30 \%$ & $40 \%$ & $50 \%$ \\
\hline Ethylene glycol & $48 / 49(98)^{a}$ & $42 / 50(84)^{a}$ & $0 / 40(0)^{b}$ \\
\hline Glycero! & $44 / 50(88)^{2}$ & $1 / 40(3)^{b}$ & N.t. \\
\hline Propylene glycol & $8 / 49(16)^{b}$ & $0 / 40(0)^{b}$ & N.t. \\
\hline
\end{tabular}

\section{Vitrification test of media}

As shown in Table 2, when ethylene glycol and glycerol were diluted to $30 \%$ with PB1 or PB1 medium containing Ficoll or Ficoll + sucrose, all the media remained transparent after cooling in liquid nitrogen. However, within $1 \mathrm{sec}$ of immersion in $20^{\circ} \mathrm{C}$ water, straws turned opaque, which is a sign of crystallization. Solutions containing $40 \%$ ethylene glycol or glycerol also remained transparent when plunged into liquid nitrogen. At warming, solutions diluted in PB1 medium without non-permeable agents again turned opaque, but media containing Ficoll remained transparent. There was no difference between the effects of ethylene glycol and glycerol as permeable agents on the occurrence of crystallization. 
Table 2. Occurrence of crystallization in various media during rapid cooling in liquid nitrogen and warming in $20^{\circ} \mathrm{C}$ water*

\begin{tabular}{|c|c|c|c|c|c|}
\hline \multirow{2}{*}{\multicolumn{2}{|c|}{ Media }} & \multicolumn{4}{|c|}{ Concentration of permeable cryoprotectants } \\
\hline & & \multicolumn{2}{|c|}{$30 \%$} & \multicolumn{2}{|c|}{$40 \%$} \\
\hline $\begin{array}{l}\text { Permeable } \\
\text { cryoprotectants }\end{array}$ & Diluents & Cooling & Warming & Cooling & Warming \\
\hline Ethylene glycol & $\begin{array}{l}\text { PB1 } \\
30 \% \text { Ficoll in PB1 } \\
30 \% \text { Ficoll }+0.5 \mathrm{M} \text {-sucrose in PB1 }\end{array}$ & $\begin{array}{l}- \\
- \\
-\end{array}$ & $\begin{array}{l}+ \\
+ \\
+\end{array}$ & $\begin{array}{l}- \\
- \\
-\end{array}$ & $\begin{array}{l}+ \\
- \\
-\end{array}$ \\
\hline Glycerol & $\begin{array}{l}\text { PB1 } \\
30 \% \text { Ficoll in PB1 } \\
30 \% \text { Ficoll }+0.5 \mathrm{M} \text {-sucrose in } \mathrm{PB} 1\end{array}$ & $\begin{array}{l}- \\
- \\
-\end{array}$ & $\begin{array}{l}+ \\
+ \\
+\end{array}$ & $\begin{array}{l}- \\
- \\
-\end{array}$ & $\begin{array}{l}+ \\
- \\
-\end{array}$ \\
\hline
\end{tabular}

*Transparent samples were considered uncrystallized and were scored $(-)$, and opaque samples were considered crystallized and were scored $(+)$.

\section{Toxicity test of vitrification solutions}

The toxicity of vitrification solutions containing ethylene glycol and the impermeable solutes Ficoll and sucrose are shown in Table 3. Survival rates of mouse embryos decreased with increasing durations of exposure in either solution. However, the toxicity of EFS solution was significantly lower than that of EF solution, and virtually no decrease in in-vitro survival of the embryos was observed after exposure to EFS solution for $5 \mathrm{~min}$ at $20^{\circ} \mathrm{C}$ ( $98 \%$ survival).

Table 3. Survival of mouse morulae exposed to vitrification solutions at $20^{\circ} \mathrm{C}$

\begin{tabular}{lcccc}
\hline & \multicolumn{4}{c}{ No. of embryos developed/no. of embryos treated (\%) } \\
\cline { 2 - 5 } Solution & 5 & 10 & 15 & 20 \\
\hline EF & $26 / 50(52)^{\mathrm{ab}}$ & $12 / 50(24)^{\mathrm{cd}}$ & $0 / 48(0)^{\mathrm{ef}}$ & $0 / 39(0)^{\mathrm{g}}$ \\
EFS & $49 / 50(98)^{\mathrm{a}}$ & $40 / 50(80)^{\mathrm{bc}}$ & $39 / 50(78)^{\mathrm{de}}$ & $10 / 50(20)^{\mathrm{fg}}$ \\
\hline
\end{tabular}

Values with the same superscripts are significantly different $(a-a, c-c, d-d, e-e, f-f$, $P<0.001 ; \mathrm{b}-\mathrm{b}, \mathrm{g}-\mathrm{g}, P<0.01)$.

\section{Vitrification of embryos}

In total, 274 ICR mouse morulae were vitrified in EFS solution, and $261(95 \%)$ were recovered after warming. When embryos had been equilibrated for $10 \mathrm{~min}$, the proportion of embyros which developed in culture was $77 \%$ (Table 4), but when they were vitrified after 2 or $5 \mathrm{~min}$ of equilibration, nearly all the recovered embryos were morphologically intact and a high percentage of them developed to expanded blastocysts in culture (97-98\%, Table 4). Of 185 vitrified F1 embryos, 178 $(96 \%)$ were recovered, $175(98 \%)$ of which were morphologically normal and were considered transferable: 167 of them were successfully transferred to 16 recipient mice, 11 of which delivered young ( 5 embryos were lost during transfer, and 3 were not transferred). Of 112 embryos which had been transferred to recipients that established pregnancy, $57(51 \%)$ developed to live young and 6 $(5 \%)$ were stillbirths. There was no difference among groups treated for $2 \mathrm{~min}$ and $5 \mathrm{~min}$ before cooling. All of them had pigmented eyes, confirming that they were derived from vitrified embryos. $_{3 \mathrm{AM}}$ 
Table 4. Survival of mouse morulae stored at $-196^{\circ} \mathrm{C}$ by vitrification in EFS solution

\begin{tabular}{lccc}
\hline $\begin{array}{l}\text { Equilibration } \\
\text { period (min) }\end{array}$ & $\begin{array}{c}\text { No. of } \\
\text { embryos } \\
\text { stored }\end{array}$ & $\begin{array}{c}\text { No. of } \\
\text { embryos } \\
\text { recovered }\end{array}$ & $\begin{array}{c}\text { No. of embryos } \\
\text { developed to } \\
\text { expanded blastocysts } \\
\text { in culture (\%) }\end{array}$ \\
\hline 2 & 104 & 99 & $97(98)^{\mathrm{a}}$ \\
5 & 111 & 106 & $103(97)^{\mathrm{a}}$ \\
10 & 59 & 56 & $43(77)^{\mathrm{b}}$ \\
\hline
\end{tabular}

*Percentage of recovered embryos.

Values with different superscripts are significantly different (a-b, $P<0.001)$.

\section{Discussion}

Vitrification is defined as "the solidification of a liquid brought about not by crystallization but by an extreme elevation in viscosity during cooling" (Fahy et al., 1984). Because the vitrified solution is normally supercooled at a low temperature, it can be crystallized (devitrified) during warming, which leads to the death of the cells suspended in it (Rall, 1987). In order to make a solution vitrify in liquid nitrogen and prevent crystallization during warming, the presence of high concentrations of permeable cryoprotective agents is essential. The first successful solution for vitrifying mouse embryos (VS1; Rall \& Fahy, 1985) contained dimethyl sulphoxide, acetamide and propylene glycol as permeable agents. Thereafter, glycerol and propylene glycol were reported effective for vitrifying mouse embryos both in combination (Scheffen et al., 1986) or as single permeating cryoprotectants (Rall, 1987).

For the present experiment on the toxicity of individual cryoprotectants, a selection was made of glycerol and propylene glycol, along with ethylene glycol, which was proved effective for freezing mouse embyros (Miyamoto \& Ishibashi, 1977; Kasai et al., 1981). As the toxicity of cryoprotectants is related to temperature, the ambient temperature for embryo manipulation was strictly controlled at $20 \pm 0.5^{\circ} \mathrm{C}$. The results show that ethyene glycol is the least toxic of the three (Table 1) in spite of the higher molecular concentration of the solution $(40 \%$ of ethylene glycol, glycerol and propylene glycol are approximately $7 \cdot 2,5 \cdot 5$ and $5 \cdot 5 \mathrm{M}$, respectively).

Definitive evidence for vitrification requires the use of physical procedures such as X-ray diffraction, calorimetry, or freeze-fracture ultramicroscopy (Rall, 1987), because ice crystals smaller than the wavelength of light will not be detected by visual inspection (Meryman, 1958). However, it has been reported that when several vitrification solutions are cooled and warmed rapidly, there is no evidence of crystallization according to appearance or calorimetry (Rall, 1987). In the present study, therefore, apparent transparency was the criterion for non-crystallization.

It has been shown that the inclusion of a macromolecule in a solution facilitates vitrification (Fahy et al., 1984), and polyethylene glycol is widely used for this purpose (Rall \& Fahy, 1985; Rall, 1987). Here, Ficoll 70 was used as a macromolecule, because it has high solubility with low viscosity. The present experiment on vitrification of various media indicates that Ficoll facilitates non-crystallization by preventing devitrification during warming (Table 2). Preliminary data showed that $30 \%$ Ficoll in PB1 medium is non-toxic to mouse embryos during $20 \mathrm{~min}$ of exposure at $20^{\circ} \mathrm{C}$ (in-vitro survival was $100 \%$, data not shown).

However, when Ficoll is added to $40 \%$ ethylene glycol (EF solution), it increased the toxicity of the ethylene glycol solution: 30\% Ficoll (w/v) seems non-toxic but Ficoll occupies about $11 \%(\mathrm{v} / \mathrm{v})$ of the EF and EFS solutions. If Ficoll were excluded from the EF and EFS solutions, the concentration of ethylene glycol would, therefore, be about $45 \%$ in both solutions, which would have increased toxicity. Fortunately, the further addition of $0.3 \mathrm{M}$-sucrose (EFS solution) decreased this 
toxic injury (Table 3). In our toxicity test of the EF and EFS solutions (Table 3), embryos treated in EF solution were suspended in EFS solution for $5 \mathrm{~min}$ before removing cryoprotectants in S-PB1, whereas embryos in EFS solution were directly transferred to S-PB 1 after treatment. Embryos in the EF solution were therefore exposed to ethylene glycol + Ficoll 5 min longer than those in EFS solution at the same equilibration period. However, survival rates of embryos exposed to EF solution for 5,10 or $15 \mathrm{~min}$ were significantly lower $(P<0 \cdot 01,0.001$ and 0.001 , respectively) than for those exposed to EFS solution for 10,15 or $20 \mathrm{~min}$, respectively. Sucrose may reduce toxicity associated with Ficoll by causing the embryos to shrink rapidly and reducing the amount of ethylene glycol in the cells. It has been reported that the addition of sucrose reduces glycerol permeation (Széll \& Shelton, 1986b).

After vitrification and warming, in-vitro survival rates of the embryos which had been equilibrated for 5 and $10 \mathrm{~min}$ in EFS solution (97 and 77\%, respectively, Table 4) were as high as those of embryos exposed to EFS solution for the same periods without cooling (98 and 80\%, respectively, Table 3 ). Therefore, there seems to be no decrease in in-vitro viability by vitrifying embryos. Although the proportion of live young was not very high $(51 \%)$, it may be possible to elevate it by refinement of the transfer technique, considering the high in-vitro viability.

The new vitrification solution described here (EFS solution) is based on ethylene glycol as the permeating cryoprotectant and two non-permeating agents, Ficoll and sucrose. Although ethylene glycol is less commonly used for embryo freezing than dimethyl sulphoxide and glycerol, the present study indicates that it has an advantage of lower toxicity. Ficoll was found effective for vitrification of embryos for the first time. Sucrose, however, has been successfully used for freezing eggs and embryos in combination with dimethyl sulphoxide (Kasai et al., 1979; Trounson et al., 1987), propylene glycol (Renard et al., 1984), and glycerol (Széll \& Shelton, 1986a). Sucrose also facilitates removal of intracellular cryoprotectants during dilution (Leibo \& Mazur, 1978; Kasai et al., 1980).

For successful embryo preservation by vitrification, permeation of a cryoprotectant is considered essential, although full permeation is not necessary but rather harmful (Rall, 1987). In the original method of vitrification (Rall \& Fahy, 1985; Rall, 1987), embryos are first equilibrated in $25 \%$ of a vitrification solution at $\sim 20^{\circ} \mathrm{C}$ for permeation of cryoprotectants before dehydration at $4^{\circ} \mathrm{C}$. In a supplementary experiment, we have observed that mouse morulae suspended in $40 \%$ ethylene glycol in $\mathrm{PB} 1$ medium at $20^{\circ} \mathrm{C}$ shrink rapidly and regain most of their volume within 5 min (data not shown), indicating rapid permeation of ethylene glycol into the embryos. In EFS solution, on the other hand, embryos remain shrunken because of the presence of sucrose. As discussed above, sucrose may reduce the amount of intracellular cryoprotectant (Széll \& Shelton, 1986b), but in the present conditions, the amount of ethylene glycol which penetrates into the embryos during 2-5 min of equilibration in EFS solution at $20^{\circ} \mathrm{C}$ seems enough for survival.

Besides giving high survival, this method for embryo preservation, using EFS solution, would be very simple. A time of 2-5 min would be enough to pretreat embryos for equilibration and loading into a straw before plunging into liquid nitrogen. Furthermore, embryos can be manipulated at room temperature $\left(20^{\circ} \mathrm{C}\right)$. This new method of vitrification may offer a simple and reliable means for embryo preservation.

This work was supported by a grant-in-aid for scientific research from the Ministry of Education, Science and Culture, Japan.

\section{References}

Fahy, G.M., MacFarlane, D.R., Angell, C.A. \& Meryman, H.T. (1984) Vitrification as an approach to cryopreservation. Cryobiology 21, 407-426.
Kasai, M., Iritani, A. \& Chang, M.C. (1979) Fertilization in vitro of rat ovarian oocytes after freezing and thawing Biol. Reprod 21, 839-844 
Kasai, M., Niwa, K. \& Iritani, A. (1980) Survival of mouse embryos frozen and thawed rapidly. $J$. Reprod. Fert. 59, 51-56.

Kasai, M., Niwa, K. \& Iritani, A. (1981) Effects of various cryoprotective agents on the survival of unfrozen and frozen mouse embryos. J. Reprod. Fert. 63, $175-180$

Leibo, S.P. \& Mazur, P. (1978) Methods for the preservation of mammalian embryos by freezing. In Methods in Mammalian Reproduction, pp. 179-201. Ed. J. C. Daniel, Jr. Academic Press, New York.

Meryman, H.T. (1958) X-ray analysis of rapidly frozen gelatin gels. Biodynamica 8, 69-72.

Miyamoto, H. \& Ishibashi, T. (1977) Survival of frozenthawed mouse and rat embryos in the presence of ethylene glycol. J. Reprod. Fert. 50, 373-375.

Miyamoto, H. \& Ishibashi, T. (1986) Liquid nitrogen vapour freezing of mouse embryos. J. Reprod. Fert. 78, 47I-478.

Rall, W.F. (1987) Factors affecting the survival of mouse embryos cryopreserved by vitrification. Cryobiology 24, 387-402.

Rall, W.F. \& Fahy, G.M. (1985) Ice-free cryopreservation of mouse embryos at $-196^{\circ} \mathrm{C}$ by vitrification. Nature, Lond. 313, 573-575.

Renard, J.P., Bui-Xuan-Nguyen \& Garnier, V. (1984) Two-step freezing of two-cell rabbit embryos after partial dehydration at room temperature. $J$. Reprod. Fert. 71, 573-580.

Scheffen, B., Van Der Zwalmen, P. \& Massip, A. (1986) A simple and efficient procedure for preservation of mouse embryos by vitrification. Cryo-Letters 7, $260-269$.

Széll, A. \& Shelton, J.N. (1986a) Sucrose dilution of glycerol from mouse embryos frozen rapidly in liquid nitrogen vapour. J. Reprod. Fert. 76, 401-408.

Széll, A. \& Shelton, J.N. (1986b) Role of equilibration before rapid freezing of mouse embryos. J. Reprod. Fert. 78, 699-703.

Toyoda, Y. \& Chang, M.C. (1974) Fertilization of rat eggs in vitro by epididymal spermatozoa and the development of eggs following transfer. J. Reprod. Fert. 36, 9-22.

Trounson, A., Peura, A. \& Kirby, C. (1987) Ultrarapid freezing: a new low-cost and effective method of embryo cryopreservation. Fert. Steril. 48, 843-850.

Whittingham, D.G. (1971) Survival of mouse embryos after freezing and thawing. Nature, London. 233, 125-126.

Whittingham, D.G., Leibo, S.P. \& Mazur, P. (1972) Survival of mouse embryos frozen to $-196^{\circ} \mathrm{C}$ and $-269^{\circ} \mathrm{C}$. Science, $N Y 178,411-414$.

Wood, M.J. \& Farrant, J. (1980) Preservation of mouse embryos by two-step freezing. Cryobiology 17 , $178-180$.

Wood, M.J., Whittingham, D.G. \& Rall, W.F. (1987) The low temperature preservation of mouse oocytes and embryos. In Mammalian Development-A Practical Approach, pp. 255-280. Ed. M. Monk. IRL Press, Oxford.

Received 28 July 1989 